\title{
Ephedrae herba stimulates hepatocyte growth factor-induced MET endocytosis and downregulation via early/late endocytic pathways in gefitinib-resistant human lung cancer cells
}

\author{
YUKIO NISHIMURA ${ }^{1}$, SUMIKO HYUGA ${ }^{2}$, SOICHI TAKIGUCHI ${ }^{3}$, MASASHI HYUGA ${ }^{4}$, \\ KAZUYUKI ITOH ${ }^{5,6}$ and TOSHIHIKO HANAWA ${ }^{2}$
}

\author{
${ }^{1}$ Division of Pharmaceutical Cell Biology, Graduate School of Pharmaceutical Sciences, Kyushu University, \\ Fukuoka 812-8582; ${ }^{2}$ Department of Clinical Research, Oriental Medicine Research Center of Kitasato University, \\ Tokyo 108-8642; ${ }^{3}$ Institute for Clinical Research, National Kyushu Cancer Center, Fukuoka 811-1395; \\ ${ }^{4}$ Division of Biological Chemistry and Biologicals, National Institute of Health Sciences, Tokyo 158-8501; \\ ${ }^{5}$ Department of Biology, Osaka Medical Center for Cancer and Cardiovascular Diseases, Osaka 537-8511, Japan
}

Received November 19, 2015; Accepted December 23, 2015

DOI: $10.3892 /$ ijo.2016.3426

\begin{abstract}
The MET tyrosine kinase receptor and its ligand, hepatocyte growth factor (HGF), are known to be overexpressed in a variety of malignant tumor cells, and are implicated in the development of gefitinib-resistance in human non-small cell lung cancer (NSCLC) cells. Ephedrae herba was previously reported to prevent HGF-induced cancer cell motility by directly suppressing HGF/MET signaling through the inhibition of MET tyrosine kinase, and treatment with its extract also considerably reduced MET protein levels. To further investigate the mechanism underlying the Ephedrae herba-induced inhibition of MET phosphorylation as well as its degradation and subsequent disappearance, we examined the effect of Ephedrae herba on HGF-stimulated MET endocytosis and downregulation via early/late endocytic pathways in an NSCLC cell line. Using immunofluorescence microscopy, we found that pretreatment of cells with Ephedrae herba extract dramatically changed the intracellular distribution of plasma membrane-associated MET, and that the resultant MET staining was distributed throughout the cytoplasm.
\end{abstract}

Correspondence to: Dr Yukio Nishimura, Division of Pharmaceutical Cell Biology, Graduate School of Pharmaceutical Sciences, Kyushu University, 3-1-1 Maidashi, Higashi-ku, Fukuoka 812-8582, Japan

E-mail: ynkio443@gmail.com

Present address: ${ }^{6}$ Research Institute, Nozaki Tokushukai Hospital, Daito City, Osaka 574-0074, Japan

Abbreviations: HGF, hepatocyte growth factor; p-MET, phosphorylated MET; EGFR, epidermal growth factor receptor; p-EGFR, phosphorylated EGFR; NSCLC, non-small cell lung cancer

Key words: Ephedrae herba, hepatocyte growth factor, MET, p-MET, endocytosis, endosomes/lysosomes, non-small cell lung cancer
Pretreatment of the cells with Ephedrae herba extract also led to the rapid loss of MET and phosphorylated (p)-MET in HGF-stimulated cells. In contrast, inefficient endocytic delivery of MET and p-MET from early to late endosomes was observed in the absence of Ephedrae herba extract, since considerable amounts of the internalized MET accumulated in the early endosomes and were not delivered to lysosomes up to $1 \mathrm{~h}$ after HGF-stimulation. Furthermore, large amounts of MET and p-MET that had accumulated in late endosomes of Ephedrae herba-pretreated cells after HGF stimulation were observed along with bafilomycin A1. Therefore, we inferred that degradation of MET occurred in the late endosome/ lysosome pathway. Moreover, western blot analysis revealed the accelerated degradation of MET and p-MET proceeds in cells pretreated with Ephedrae herba extract. Collectively, our results suggest that some components of Ephedrae herba have a novel role in promoting HGF-stimulated MET and p-MET endocytosis followed by its downregulation, likely mediated by the early/late endocytic pathways.

\section{Introduction}

MET tyrosine kinase receptor is overexpressed in a variety of cancers (1-3), which could be the result of the MET gene amplification, which has been observed, particularly in transcriptional activation in a small subset of cancers (4-8), and more recently in lung cancers $(9,10)$. Signaling by MET and its ligand, hepatocyte growth factor (HGF) (11), is known to play an important role in increased cell proliferation, reduced apoptosis, invasion, scattering, increased metastasis, and angiogenesis $(12,13)$.

The dimerization and autophosphorylation of MET receptors occur following HGF binding, leading to the activation of pathways such as mitogen-activated protein kinase (MAPK), phosphatidylinositol-3-kinase (PI3K)-serine/threonine kinase AKT (AKT), and the signal transducers and activator of transcription (STAT) signaling (14-16). Then, the HGF-induced MET receptors are internalized and trafficked to the early endosomes commonly referred to as the sorting endosomes. In 
the sorting endosomes, MET receptors are ubiquitinated and are recognized by the endosomal sorting complex required for transport (ESCRT) machinery that generates multivesicular bodies (MVBs) by packaging molecular cargo into small vesicles that bud off from the limiting membrane into the lumen of the endosomes (17). Accordingly, endocytosis and downregulation of HGF-MET complexes are closely related to the attenuation of intracellular MET signaling $(18,19)$. Alternatively, MET is recycled to the plasma membrane by endosomal recycling pathways (20).

Maoto, a traditional Kampo medicine, has been suggested to prevent cancer metastasis by directly suppressing the metastatic ability of cancer cells, based on its inhibition of the serum-induced motility of human breast cancer and mouse osteosarcoma cells (21-23). Maoto is composed of four ingredients, namely Ephedrae herba, Armeniacae semen, Cinnamomi cortex, and Glycyrrhizae radix. Furthermore, extracts of maoto and Ephedrae herba were both previously shown to prevent HGF-induced cancer cell motility by inhibiting HGF/MET/AKT signaling through the suppression of MET phosphorylation kinase $(23,24)$. In addition, Ephedrae herba directly inhibited the tyrosine-kinase activity of MET as well as phosphorylation of AKT, a downstream target of MET. Moreover, MET protein and gene expression was considerably reduced following 24-h treatment with maoto or Ephedrae herba exracts, and these inhibitory effects were abrogated by the removal of Ephedrae herba from the incubation medium $(23,24)$. Thus, these suppressive effects may be attributed to Ephedrae herba. Further, it has recently been demonstrated that herbacetin glycosides (25), which are active molecules found in Ephedrae herba and their aglycon, herbacetin, inhibits HGF-MET-AKT signaling in human MDA-MB-231 breast cancer cells (26). However, it was also shown that herbacetin treatment does not affect MET protein expression in these cells. Accordingly, we surmised that some other components of Ephedrae herba extract might have a stimulatory influence on the HGF-induced MET endocytosis via the early/late endocytic pathways.

Therefore, in this study, we investigated the molecular mechanisms by which Ephedrae herba inhibits the phosphorylation of MET and decreases MET protein expression. Specifically, we examined the effect of Ephedrae herba on HGF-stimulated MET endocytosis and its downregulation via the early/late endocytic pathways in the H1993 NSCLC cell line, harboring MET gene amplification and MET overexpression (10), using immunofluorescence microscopy and western blot analysis. We found that the pretreatment of cells with Ephedrae herba not only led to a considerably suppressed MET/AKT phosphorylation, but also plasma membraneassociated MET was rapidly endocytosed and subsequently downregulated via the early/late endocytic pathways in the cells. Taken together, our results led us to infer that components of Ephedrae herba might play a novel role in promoting HGF-stimulated MET/p-MET endocytosis and subsequent degradation in the early/late endocytic pathways.

\section{Materials and methods}

Materials. Ephedrae herba was purchased from Tsumura \& Co. (Tokyo, Japan) and was mixed with RPMI medium to a concentration of $10 \mathrm{mg} / \mathrm{ml}$ at $37^{\circ} \mathrm{C}$ for $30 \mathrm{~min}$. Recombinant human HGF was purchased from PeproTech (London, UK). Bafilomycin A1, cycloheximide (CHX), and DAPI were obtained from Sigma (St. Louis, MO, USA). SlowFade antifade reagent was purchased from Molecular Probes (Eugene, OR, USA). Other chemicals were of reagent grade and were obtained from commercial sources.

Cell culture. The human H1993 non-small cell lung cancer cell line was obtained from the American Type Culture Collection. Cells were cultured at $37^{\circ} \mathrm{C}$ and $5 \% \mathrm{CO}_{2}$ in RPMI-1640 containing $10 \%$ fetal bovine serum (FBS) in a humid environment. The serum-starved cells were preincubated with Ephedrae herba extract $(100 \mu \mathrm{g} / \mathrm{ml})$ at $37^{\circ} \mathrm{C}$ for $2 \mathrm{~h}$ and $0.17 \mu \mathrm{M}$ bafilomycin $\mathrm{A} 1$ for $30 \mathrm{~min}$, and then stimulated with HGF $(50 \mathrm{ng} / \mathrm{ml})$ at $37^{\circ} \mathrm{C}$ for the indicated times, after which further analysis was performed.

Antibodies. Alexa 488-labeled or Texas red-labeled goat antimouse and goat anti-rabbit secondary antibodies were obtained from Molecular Probes. Normal rabbit IgG and normal mouse monoclonal IgG1 were purchased from Imgenex (San Diego, CA, USA) and Angio-proteomie (Boston, MA, USA), respectively. Normal goat serum was purchased from Sigma. Anti-MET, phospho-MET (p-MET), AKT, phospho-AKT ${ }^{\mathrm{S} 473}$ $\left(\mathrm{p}-\mathrm{AKT}^{\mathrm{S} 473}\right.$ ), p44/42 MAPK (MAPK), phospho-p44/42 MAPK (p-MAPK), EEA1, and LAMP1 antibodies were obtained from Cell Signaling Technology (Beverly, MA, USA), and anti- $\beta$-actin antibody was obtained from Sigma. Mouse monoclonal antibody to SNX1 was purchased from BD Biosciences (San Jose, CA, USA). Mouse monoclonal anti-HGF $\alpha$-chain antibody was purchased from Institute of Immunology (Tokyo, Japan). Anti-cathepsin D was affinitypurified by protein A Sepharose CL-4B (Sigma), followed by immunoaffinity chromatography using antigen-conjugated Sepharose 4B as previously described $(27,28)$.

Immunofluorescence microscopy (General procedures). Immunofluorescence microscopy was described previously (29-32). H1993 cells were grown for 2 days on glass coverslips in 6-well plates in RPMI with $10 \%$ fetal bovine serum. Cells pretreated with or without Ephedrae herba extract $(100 \mu \mathrm{g} / \mathrm{ml})$ at $37^{\circ} \mathrm{C}$ for $4 \mathrm{~h}$ were fixed with $3.7 \%$ formaldehyde in phosphate-buffered saline (PBS), $\mathrm{pH} 7.4$, permeabilized in PBS containing $0.1 \%$ saponin. After washing with PBS, cells were blocked with PBS-10\% normal goat serum. All subsequent antibody and wash solutions contained $0.1 \%$ saponin. H1993 cells were then double-stained for MET with anti-MET antibody and SNX1 with anti-SNX1 antibody or LAMP1 with anti-LAMP1 antibody, or for p-MET with anti-p-MET antibody and SNX1 with anti-SNX1 antibody or LAMP1 with anti-LAMP1 antibody. Early endosomes were stained with anti-SNX1 antibody, since SNX1 protein is a family of sorting nexin proteins, and are localized to early endosomes $(33,34)$.

Late endosomes/lysosomes were stained with anti-LAMP1 antibody, since the LAMP1 protein is distributed within endocytic organelles and is at its highest concentration in the late endosomes/lysosomes, as observed for other lysosomal glycoproteins, namely, lysosomal-associated membrane protein-1 (LAMP-1) and LAMP-2 $(35,36)$. The cells were then 
incubated for $1 \mathrm{~h}$ with the secondary antibodies at $20 \mu \mathrm{g} / \mathrm{ml}$ and was further stained with DAPI to reveal nuclei. Controls for antibody specificity were non-immune normal mouse IgG1 or non-immune normal rabbit IgG. The distribution of the labeled proteins was then analyzed by confocal immunofluorescence microscopy of the fixed cells. Slides were mounted with SlowFade anti-fade reagent and observed on a Zeiss LSM 510 META confocal laser scanning microscope (Carl Zeiss, Oberkochen, Germany), equipped with krypton/argon laser sources. Colocalization of MET and SNX1 or LAMP1, p-MET and SNX1 or LAMP1 was quantified using ImageJ software and the MacSCOPE X software (Mitani Corporation, Osaka, Japan).

Immunofluorescence microscopy (Pretreatment of cells with Ephedrae herba). To clarify MET internalization, we followed the uptake of HGF with time in H1993 cell line (19). To minimize the contribution of recycling and/or lysosomal degradation of the internalized HGF, we quantified the HGF uptake in each cell for time periods of up to $60 \mathrm{~min}$. H1993 cells were starved for $3 \mathrm{~h}$ with RPMI without $\mathrm{FBS}$ at $37^{\circ} \mathrm{C}$, and the serum-starved cells pretreated with or without Ephedrae herba extract $(100 \mu \mathrm{g} / \mathrm{ml})$ for $2 \mathrm{~h}$ were then incubated with HGF $(50 \mathrm{ng} / \mathrm{ml})$ at $37^{\circ} \mathrm{C}$ for 15,30 , or $60 \mathrm{~min}$. The distribution of internalized HGF stained with anti-HGF $\alpha$-chain antibody and early endosomes with EEA1 antibody or lysosomes stained with anti-cathepsin D antibody was then assessed by confocal immunofluorescence microscopy. Early endosomes and lysosomes were stained with anti-EEA1 antibody and anti-cathepsin D antibody, respectively. In another case, cells pretreated with or without Ephedrae herba extract were starved for $3 \mathrm{~h}$ with RPMI without FBS at $37^{\circ} \mathrm{C}$ and then the phosphorylation of MET was induced with HGF for 15,30 , or $60 \mathrm{~min}$. The fixed cells were double-stained for p-MET with anti-p-MET antibody and LAMP1 with anti-LIMP1 antibody. In some cases, cells pretreated with Ephedrae herba extract were incubated with $0.17 \mu \mathrm{M}$ bafilomycin $\mathrm{A} 1$ for $30 \mathrm{~min}$ and then stimulated with $\mathrm{HGF}$ at $37^{\circ} \mathrm{C}$ for the indicated times, after which further analysis was performed.

Western blot analysis. Protein samples were separated by sodium dodecyl sulfate (SDS)-polyacrylamide gel electrophoresis (PAGE) and then transferred to polyvinylidene difluoride membranes (Millipore, Billerica, MA, USA). Following blocking, the membrane was blotted with the appropriate antibody, and subsequently, horseradish peroxidase-conjugated anti-mouse or anti-rabbit IgG (GE Healthcare Bioscience, Tokyo, Japan) was applied. The final signal was revealed by ECL chemiluminescence (Pierce, Rockford, IL, USA). Digital images were analyzed with NIH Image software to measure the density of each band without a saturated signal.

HGF-stimulated phosphorylated MET degradation. H1993 cells were starved for $12 \mathrm{~h}$ with RPMI without FBS at $37^{\circ} \mathrm{C}$. The serum-starved cells pretreated with or without Ephedrae herba extract $(100 \mu \mathrm{g} / \mathrm{ml})$ for $2 \mathrm{~h}$ were preincubated for $30 \mathrm{~min}$ in the presence of $\mathrm{CHX}(20 \mu \mathrm{g} / \mathrm{ml})$, and then the cells were incubated with $\mathrm{HGF}$ at $37^{\circ} \mathrm{C}$ for the indicated times. The cells were washed with ice-cold-PBS and lysed, followed by SDS-PAGE and western blot analysis.
Statistical analysis. Data are expressed as mean \pm SD unless otherwise noted. Significance $(\mathrm{P}<0.05)$ was determined by using Student's t-test, since all data met all the assumptions for parametric statistical analysis.

\section{Results}

Alteration of intracellular distribution of MET and phosphorylated MET in Ephedrae herba-pretreated NSCLC cells. To examine the effect of Ephedrae herba on the intracellular distribution of MET and phosphorylated (p)-MET in H1993 NSCLC cells harboring MET gene amplification and MET overexpression (10), cells were pretreated with Ephedrae herba extract $(100 \mu \mathrm{g} / \mathrm{ml})$ for $4 \mathrm{~h}$ at $37^{\circ} \mathrm{C}$ as described in the Materials and methods. The control and Ephedrae herba extract-pretreated cells were fixed, double-labeled with antibodies against to MET or p-MET and sorting nexin-1 (SNX1) or lysosomal integral membrane protein (LAMP1), and then analyzed by using confocal immunofluorescence microscopy (Fig. 1A-D). We examined the intracellular distribution of MET or p-MET with SNX1 as a marker of early endosomes, since SNX1 consists of a family of sorting nexin proteins, and approximately 25 human sorting nexins have been identified (33). In addition, SNX1 is known to interact with epidermal growth factor receptor (EGFR) (34) and are localized in early endosomes (33). We also determined the intracellular distribution of late endosomes/lysosomes by using an antibody specific to LAMP1, which is distributed in the endocytic organelles at concentrations that are highest in late endosomes/lysosomes, as has been reported for other lysosomal glycoproteins $(35,36)$.

Confocal immunofluorescence microscopy studies revealed that MET was exclusively localized on the plasma membrane at a cell-cell contact sites of H1993 cells; however, no colocalization with organelle marker proteins such as SNX1 or LAMP1 was observed. These results indicate that MET is mostly associated with the plasma membrane but not with early endosomes or late endosomes in H1993 cells (Fig. 1A and B). Further, an increased level of p-MET was associated with the plasma membranes, and p-MET-positive staining was not colocalized with other organelle marker proteins (Fig. 1C and D). In contrast, the pretreatment of cells with Ephedrae herba extract strongly decreased the intracellular distribution of the plasma membrane-associated MET and p-MET while the resultant MET and p-MET staining was spread throughout the cytoplasm (Fig. 1A-D). Ephedrae herba extract also led to the gradual disappearance of MET and phosphorylated MET in the cells. Quantitative analysis of the colocalization rate was performed and expressed as the percentage of the integrated density of SNX1-positive early endosomes (Fig. 1E) or LAMP1-positive late endosome/ lysosomes (Fig. 1F) colocalized with MET relative to total MET (\% total MET) in H1993 cells pretreated with or without Ephedrae herba extract. Our data verified that colocalization of MET with SNX1 (59.8 \pm 16.3 vs. $6.0 \pm 2.9 \%$ total MET) or LAMP1 $(52.4 \pm 14.5$ vs. $12.7 \pm 2.1 \%$ total MET) was markedly higher in the Ephedrae herba extract-pretreated cells than it was in the control cells. In addition, we observed that the colocalization of p-MET and SNX1 $(49.1 \pm 5.4$ vs. $12.9 \pm 4.8 \%$ total MET) or LAMP1 $(47.3 \pm 5.4$ vs. $14.2 \pm 4.7 \%$ total MET) 
A MET/SNX1

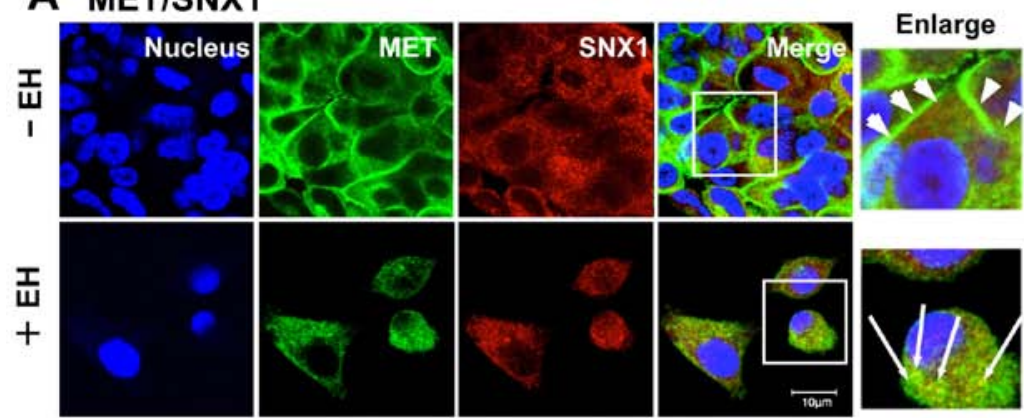

\section{B MET/LAMP1}
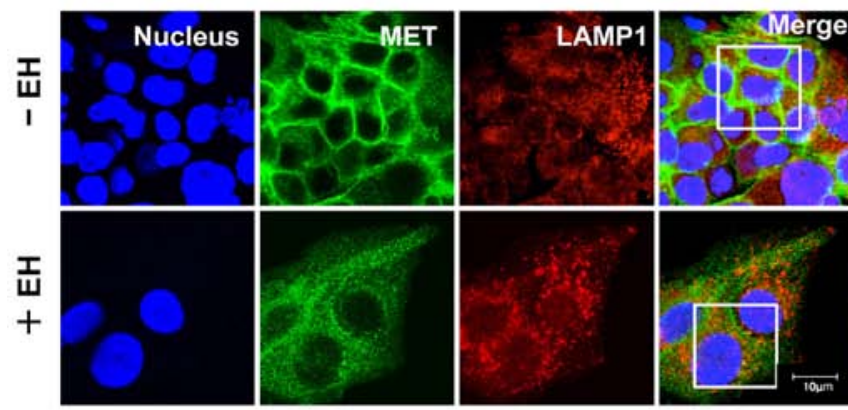

\section{PMET/SNX1}
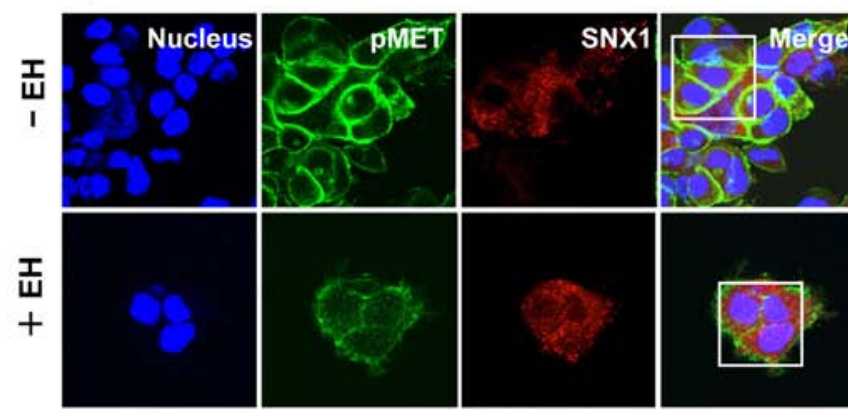

D $\mathrm{PMET} / \mathrm{LAMP1}$

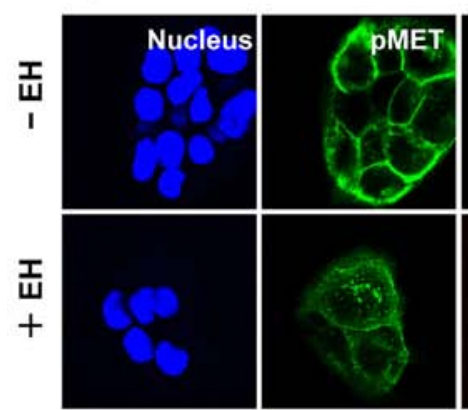

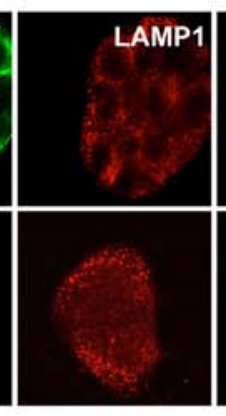

$\mathbf{E}$

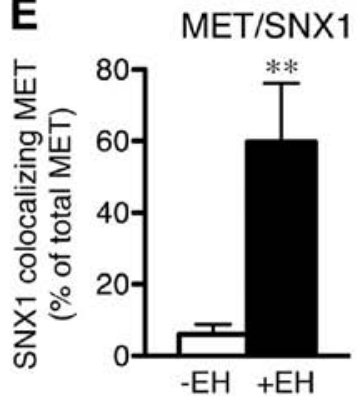

$\mathbf{F}$

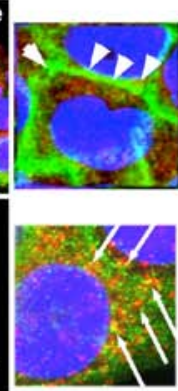

Enlarge

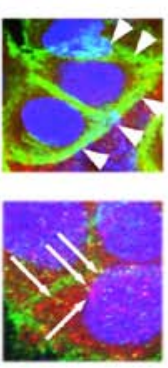

G

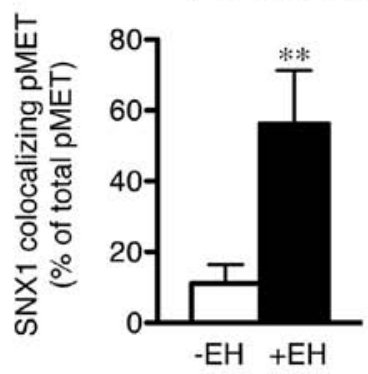

H

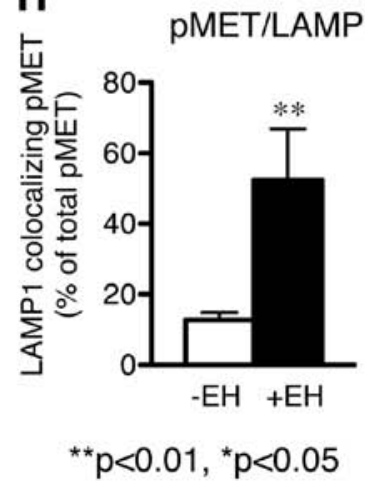

Figure 1. Effect of Ephedrae herba on intracellular distribution of MET and phosphorylated MET in the human H1993 gefitinib-resistant NSCLC cell line. The H1993 cells, harboring MET overexpression, were pretreated with Ephedrae herba extract (EH; $100 \mu \mathrm{g} / \mathrm{ml})$ for $4 \mathrm{~h}$ at $37^{\circ} \mathrm{C}$. The cells in the control (-EH) or the Ephedrae herba-pretreated groups (+EH) were fixed, double-labeled with antibodies specific to MET and SNX1 (A) or lysosomal integral membrane protein (LAMP1) (B), p-MET and SNX1 (C) or LAMP1 (D), and then analyzed by using confocal immunofluorescence microscopy as described in Materials and methods. Superimposed images of MET or p-MET and each organelle marker protein are also shown. Each cell was stained with DAPI (blue) to reveal nuclei. Bar, $10 \mu \mathrm{m}$. Right column shows the merged images of MET and SNX1 in (A), MET and LAMP1 (B), p-MET and SNX1 (C), or p-MET and LAMP1 (D) in H1993 cells pretreated with or without Ephedrae herba extract, and white squares indicate enlarged regions. The white arrowheads indicate the MET-positive staining distributed in the plasma membranes of $\mathrm{H} 1993$ cells, and the long white arrows indicate the merged confocal images as yellow color of MET or p-MET and each organelle marker proteins spread throughout the cytoplasm of each cell. The bar diagrams in (E, F, G, and H) indicate the increase of colocalized confocal images of MET or p-MET and each organelle marker proteins in H1993 cells pretreated with (black columns) or without (white columns) Ephedrae herba extract. Values are the percentage of the integrated density of SNX1 or LAMP1-colocalizing MET compared to that of total MET in (E and F), and the percentage of the integrated density of SNX1 or LAMP1-colocalizing p-MET compared to that of total p-MET in (G and H). The error bar denotes SD from three separate experiments, and significance was determined using Student's t-test. Significant difference between the values ${ }^{*} \mathrm{P}<0.05 ;{ }^{* *} \mathrm{P}<0.01$. In H1993 cells, MET and p-MET is exclusively localized in the plasma membrane at a cell-cell contact sites, however, no colocalization with organelle marker proteins such as SNX1 and LAMP1 is observed, suggesting that MET and p-MET is mainly associated with plasma membrane, but not with the early endosomes or late endosomes. In contrast, the pretreatment of cells with Ephedrae herba extract led to a rapid loss of MET and p-MET in the cells, and the resultant MET and p-MET staining was distributed throughout the cytoplasm. 
was also greater in the Ephedrae herba extract pre-treated cells than it was in the control cells (Fig. 1G and H). These results indicate that Ephedrae herba extract pretreatment abrogated the expression of MET and p-MET in the H1993 cells and, therefore, suggests that plasma membrane-associated MET or p-MET might be rapidly endocytosed and sorted to the late endosomes/lysosomes in Ephedrae herba extract-pretreated H1993 cells.

Ephedrae herba stimulates HGF-induced MET and p-MET endocytosis and subsequent degradation in human NSCLC cells. We made a novel discovery in the present study that the pretreatment of H1993 cells with Ephedrae herba extract altered the intracellular distribution of plasma membraneassociated MET and p-MET, which led to their gradual disappearance from the cells. Therefore, we inferred that some components of Ephedrae herba extract might have impaired the mechanisms of MET endocytosis that is tightly regulated by the early/late endocytic pathways.

Accordingly, to further substantiate the effect of Ephedrae herba on the HGF-mediated disappearance of MET, we investigated the endocytosis of HGF-induced MET in H1993 cells pretreated with or without Ephedrae herba extract. The Ephedrae herba extract pretreated cells were stimulated with HGF for 15, 30, or $60 \mathrm{~min}$, and then double-stained for the internalized HGF (with anti-HGF $\alpha$-chain antibody), which is regarded as HGF receptor (MET) and EEA1 (with anti-EEA1 antibody), which is a marker of early endosomes. Following its stimulation, HGF is recognized by the HGF receptor (MET) and then endocytosed via an endocytic pathway. Confocal immunofluorescence analysis confirmed that a large proportion of the intracellular HGF-positive staining disappeared in the Ephedrae herba extract-pretreated cells after 15-min of HGF-stimulation (Fig. 2A), indicating that Ephedrae herba extract pretreatment caused the gradual disappearance of MET in the cells. Furthermore, confocal immunofluorescence studies demonstrated the rapid endocytosis of HGF and small punctate vesicles, which were positively stained for internalized HGF and mostly overlapped with EEA1, and were distributed in the cytoplasm of the cells pretreated with Ephedrae herba extract for $15 \mathrm{~min}$ (Fig. 2A). The results of the quantitative analysis of the relative expression levels of HGF-positive to endogenous EEA1 staining in H1993 cells pretreated with or without Ephedrae herba extract showed fold changes of $0.73 \pm 0.1$ vs. $2.2 \pm 0.5,0.7 \pm 0.1$ vs. $2.7 \pm 0.9$, and $0.5 \pm 0.1$ vs. $2.5 \pm 0.2$ after $15,30,60 \mathrm{~min}$ of HGF-stimulation, respectively (Fig. 2D).

In contrast, endocytosis of HGF was considerably suppressed, and the internalized HGF remained localized in the plasma membranes after control cells were stimulated for 15 min with HGF (Fig. 2A). Furthermore, the endocytosed HGF-positive staining was still accumulated and colocalized with EEA1-positive early endosomes $60 \mathrm{~min}$ after internalization (Fig. 2C). The colocalization rate results confirmed that EEA1-colocalized MET was higher in the cells pretreated with Ephedrae herba extract than it was in the untreated cells after 30 and $60 \mathrm{~min}(36.5 \pm 12.8$ vs. $29.2 \pm 5.4 \%$ total MET and $52.3 \pm 8.3$ vs. $30.4 \pm 2.4 \%$ total MET) of HGF stimulation, respectively (Fig. 2E). These results show that Ephedrae herba extract pretreatment stimulated cellular HGF-induced
MET endocytosis and subsequent degradation, resulting in decreased MET protein expression.

We also examined the effect of Ephedrae herba extract on the HGF-induced p-MET endocytosis likely mediated by the early/late endocytic pathways in H1993 cells. The cells were stimulated with HGF for 15,30 , or $60 \mathrm{~min}$, and then double-stained for the internalized p-MET and LAMP1 (late endosome/lysosome marker) with anti-p-MET and anti-LAMP1 antibodies, respectively. The results revealed that a large proportion of p-MET was mostly associated with the plasma membranes of the non-pretreated cells and colocalization of p-MET with LAMP1 was not discernible even after stimulation for $60 \mathrm{~min}$ (Fig. 3). However, a considerable proportion of the intracellular p-MET-positive staining disappeared in the Ephedrae herba extract-pretreated cells after 15-min HGF-stimulation (Fig. 3A-C), indicating that the pretreatment of cells with Ephedrae herba extract almost depleted cellular p-MET.

Noteworthy, we observed a rapid endocytosis of p-MET that clearly overlapped with LAMP1 staining in the cytoplasm of the cells pretreated with Ephedrae herba extract after 15and 30-min HGF stimulation (Fig. 3A and B). In contrast, p-MET endocytosis was inhibited and a considerable amount of p-MET staining remained associated with the plasma membranes even 60 min after HGF stimulation of the control cells (Fig. 3C). The Ephedrae herba extract-induced endocytic trafficking of p-MET observed was consistent with the effect of the extract on MET endocytosis in H1993 cells. The results of the quantitative analysis of the expression of p-MET staining relative to endogenous LAMP1 with or without Ephedrae herba extract pretreatment showed fold changes of $0.4 \pm 0.1 \mathrm{vs}$. $3.1 \pm 0.4,0.5 \pm 0.1$ vs. $2.7 \pm 0.9$, and $0.5 \pm 0.1$ vs. $2.7 \pm 0.9$ after 15 , 30, and $60 \mathrm{~min}$ of HGF-stimulation, respectively (Fig. 3D). The colocalization rate determination further confirmed that LAMP1-colocalized p-MET is greater in the cells pretreated with Ephedrae herba extract than it was in the untreated cells after both 30 and 60 min HGF stimulation $(36.9 \pm 10.3$ vs. $8.5 \pm 2.6$ and $34.9 \pm 9.3$ vs. $12.2 \pm 1.6 \%$ total p-MET, respectively, Fig. 3E). These results show that some components of Ephedrae herba extract might have stimulatory activity on both HGF-induced MET and p-MET endocytosis and subsequently induce their degradation in human lung cancer cells.

Lysosomal inhibitor attenuates Ephedrae herba-stimulated MET endocytosis and MET degradation in human NSCLC cells. To further explore the mechanism by which Ephedrae herba stimulates the endocytosis of MET or p-MET and their subsequent degradation in H1993 cells, we determined if the lysosomal inhibitor, bafilomycin A1, prevented the accelerated degradation of MET or p-MET in cells pretreated with or without Ephedrae herba extract. Cells were pretreated with or without Ephedrae herba extract for $2 \mathrm{~h}$, incubated with bafilomycin A1 for $30 \mathrm{~min}$, and then were stimulated with HGF for 30 or 60 min followed by co-staining for HGF and cathepsin D or p-MET and LAMP1. The results illustrated in the confocal images showed an apparent increase in the colocalization of HGF and cathepsin D as well as p-MET and LAMP1 in the presence of bafilomycin A1 in the Ephedrae herba extractpretreated cells after 30 or 60 min of HGF stimulation (Fig. 4A and $\mathrm{B})$. The determination of the colocalization rate confirmed 

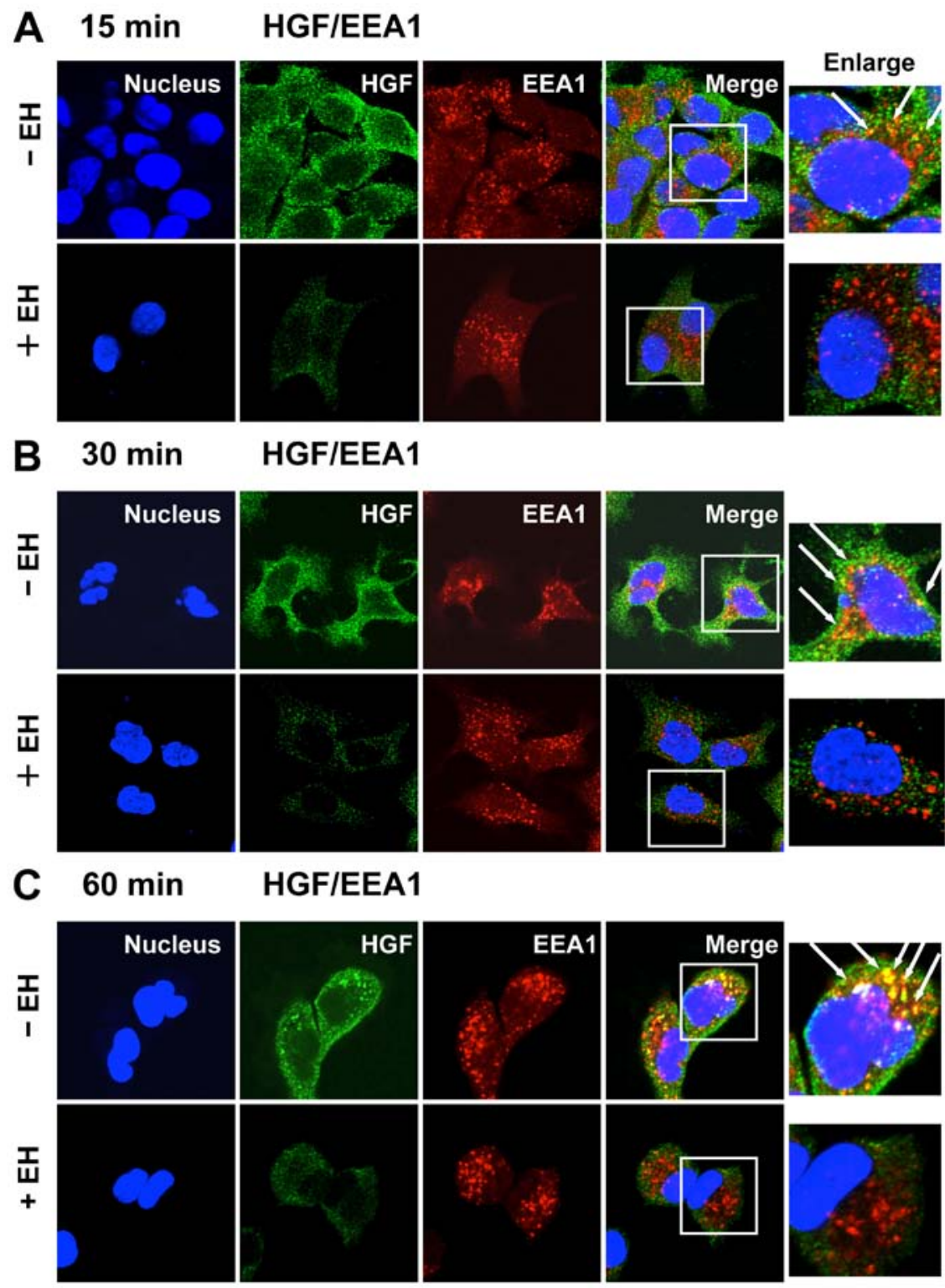

D

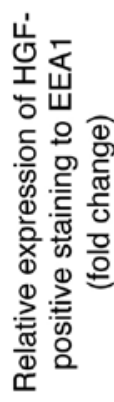

E 


\section{A $15 \mathrm{~min} \quad \mathrm{PMET} / \mathrm{LAMP1}$}
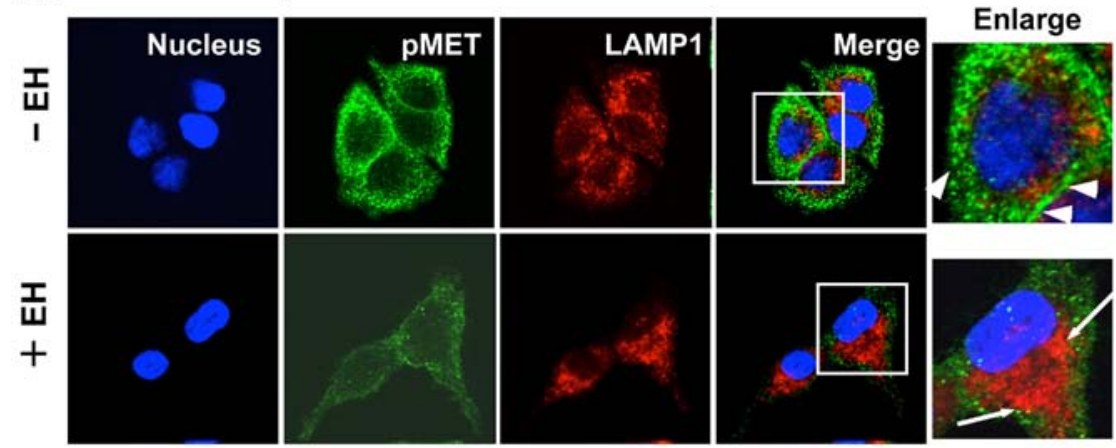

B $30 \mathrm{~min}$

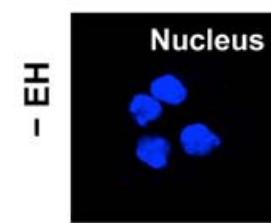

PMET/LAMP1
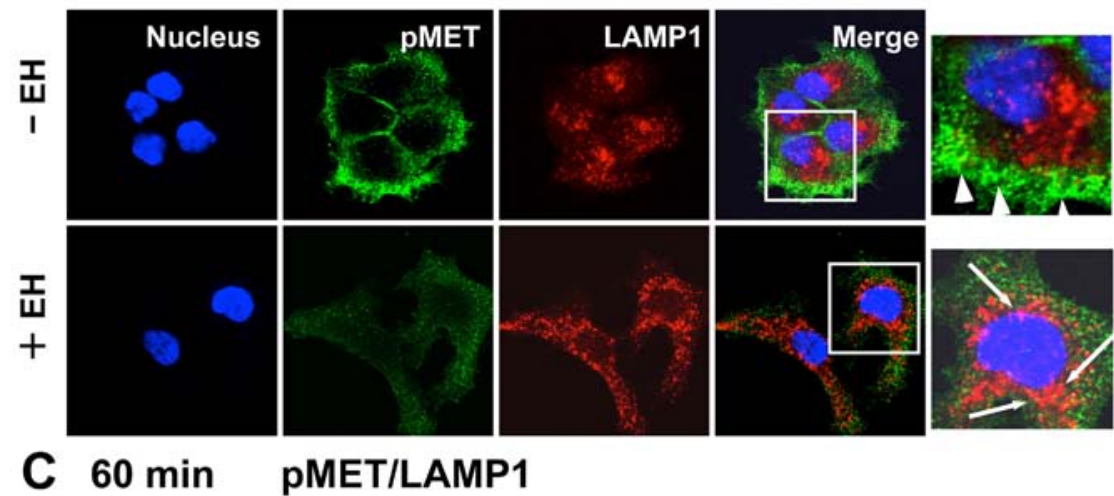

PMET/LAMP1
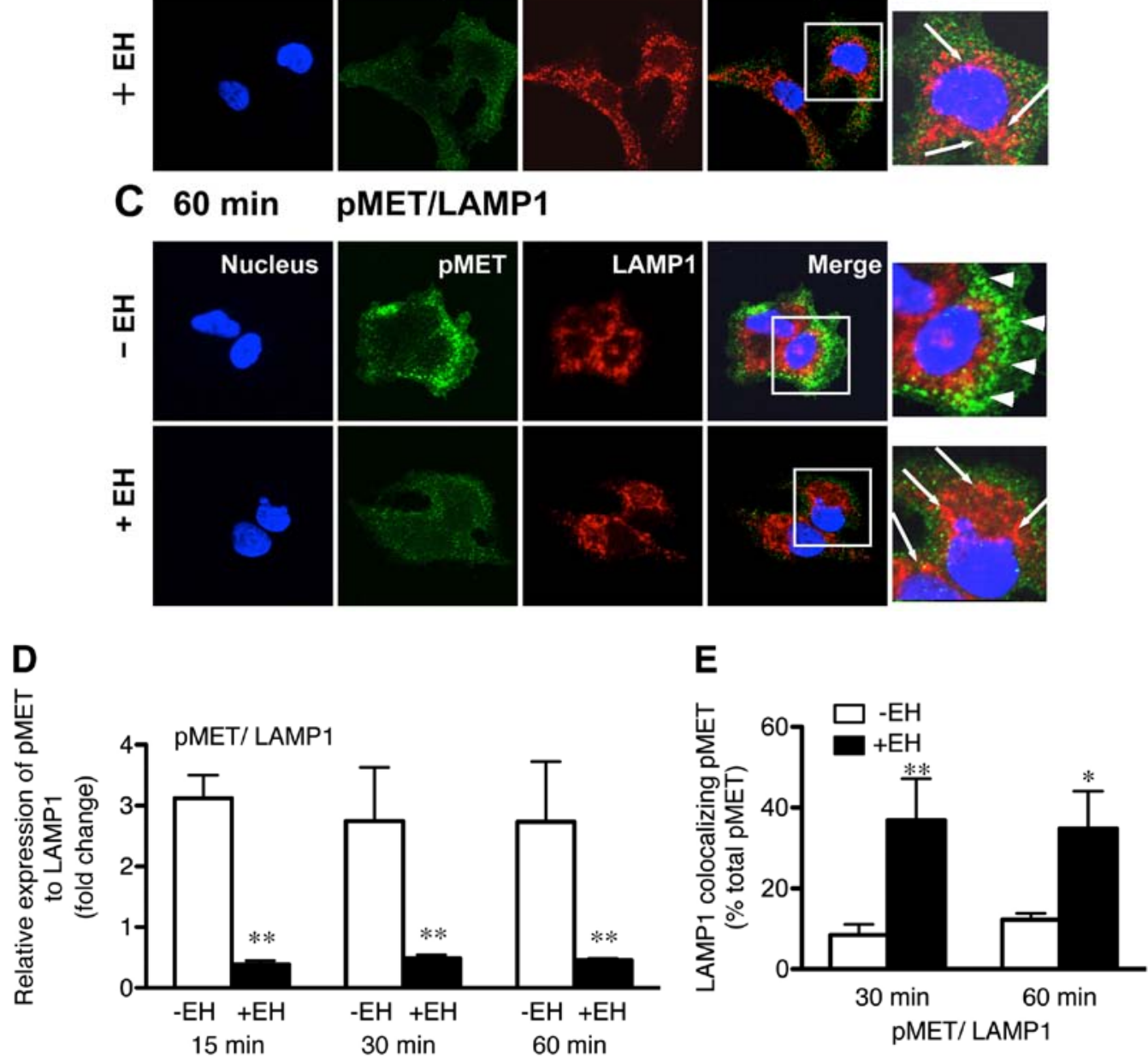

Figure 3. Ephedrae herba stimulates HGF-induced phosphorylated MET endocytosis via the early/late endocytic pathways in H1993 cells. H1993 cells were pretreated with or without Ephedrae herba extract (EH; $100 \mu \mathrm{g} / \mathrm{ml}$ ) for $2 \mathrm{~h}$ at $37^{\circ} \mathrm{C}$, and the cells in the untreated or the Ephedrae herba extract-treated groups were then incubated with $\mathrm{HGF}(50 \mathrm{ng} / \mathrm{ml})$ at $37^{\circ} \mathrm{C}$ for (A) $15 \mathrm{~min}$, (B) $30 \mathrm{~min}$, or (C) $60 \mathrm{~min}$. The distribution of internalized p-MET stained with anti-p-MET antibody and late endosomes stained with anti-LAMP1 antibody was then assessed by confocal immunofluorescence microscopy after fixation of the cells as described in Materials and methods. Superimposed images of the internalized p-MET (green) with LAMP1 (red) are shown. Each cell was stained with DAPI (blue) to reveal nuclei. Right column shows the merged images for double staining of p-MET (green) and LAMP1 (red), and white squares indicate enlarged regions. The long white arrows indicate the merged confocal images as yellow color of p-MET- and LAMP1-positive staining in the cells. (D) Quantitative analysis for the expression levels of p-MET-positive staining relative to endogenous LAMP1 staining in H1993 cells pretreated with or without Ephedrae herba extract after 15-, 30-, or 60-min HGF-stimulation are shown. Values are the fold-decrease of p-MET-positive staining relative to total EEA1-positive staining in the cells. (E) The colocalization of p-MET and LAMP1 in H1993 cells pretreated with or without Ephedrae herba extract after 30-min or 60-min HGF-stimulation are shown. Values are the percentage of the integrated density of LAMP1 that colocalizes with p-MET compared to that of total p-MET. The error bar denotes SD from three separate experiments, and significance was determined using Student's t-test. Significant difference between the values ${ }^{*} \mathrm{P}<0.05 ;{ }^{* *} \mathrm{P}<0.01$. 

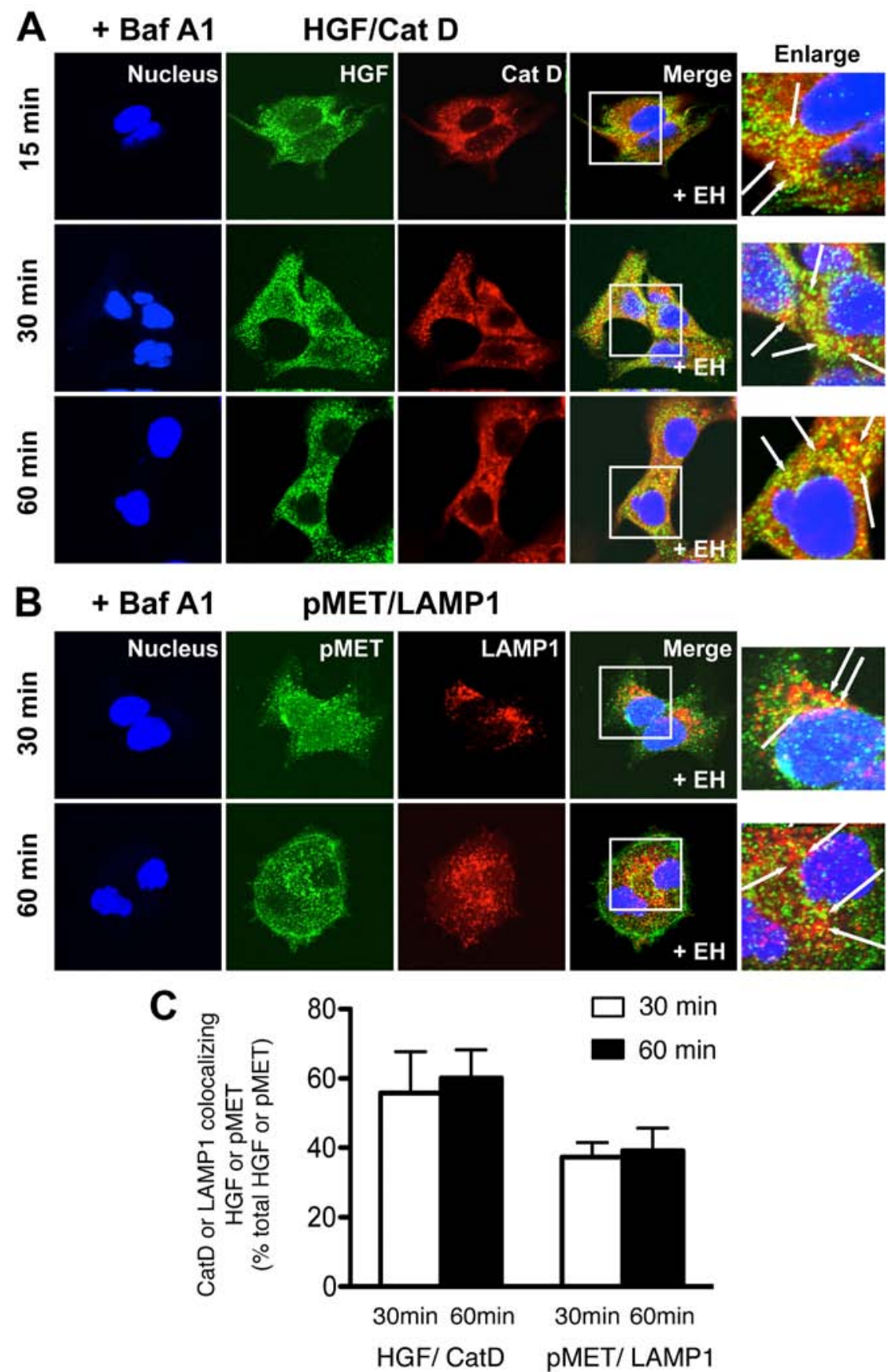

Figure 4. Bafilomycin A1 suppresses HGF-stimulated endocytosis of MET and phosphorylated MET in the Ephedrae herba extract-pretreated H1993 cells. $\mathrm{H} 1993$ cells were pretreated with Ephedrae herba extract $(\mathrm{EH} ; 100 \mu \mathrm{g} / \mathrm{ml})$ for $2 \mathrm{~h}$ at $37^{\circ} \mathrm{C}$. (A) The cells were then incubated with $\mathrm{HGF}(50 \mathrm{ng} / \mathrm{ml})$ at $37^{\circ} \mathrm{C}$ for 15,30 , or $60 \mathrm{~min}$. The distribution of internalized HGF stained with anti-HGF $\alpha$-chain antibody and lysosomes stained with anti-cathepsin D antibody was then assessed by confocal immunofluorescence microscopy after fixation of the cells as described in Materials and methods. Superimposed images of the internalized HGF (green) with cathepsin D (red) are shown. (B) The cells were incubated with $\mathrm{HGF}(50 \mathrm{ng} / \mathrm{ml})$ at $37^{\circ} \mathrm{C}$ for $30 \mathrm{~min}$ or $60 \mathrm{~min}$. The distribution of internalized p-MET stained with anti-p-MET antibody and late endosomes stained with anti-LAMP1 antibody was assessed by confocal immunofluorescence microscopy after fixation of the cells. Superimposed images of the internalized p-MET (green) with LAMP1 (red) are shown. Each cell was stained with DAPI (blue) to reveal the nuclei. Superimposed images of the internalized p-MET (green) with LAMP1 (red) are shown. Each cell was stained with DAPI (blue) to reveal the nuclei. Right column shows the merged images for double staining of HGF and cathepsin D in (A) or p-MET and LAMP1 in (B), and white squares indicate enlarged regions. The long white arrows indicate the merged confocal images as yellow color of HGF- and cathepsin D-positive staining in (A) or p-MET- and LAMP1-positive staining in (B). (C) Quantitative analysis of colocalization between HGF and cathepsin D or p-MET and LAMP1 after 30-min (white column) or 60-min (black column) HGF-stimulation in the Ephedrae herba-pretreated cells. Left panel, values are the percentage of the integrated density of cathepsin D-colocalizing HGF compared to that of total HGF. Right panel, values are the percentage of the integrated density of LAMP1-colocalizing p-MET compared to that of total p-MET. Error bar denotes SD of three separate experiments.

that cathepsin D-colocalized HGF $(60.2 \pm 8.1 \%$ total HGF) and LAMP1-colocalized p-MET $(39.2 \pm 6.5 \%$ total p-MET) were apparently higher in the cells in the presence of bafilomycin A1 and Ephedrae herba extract-pretreatment after 60 min of HGF stimulation (Fig. 4C) than in cells not treated with the lysosomal inhibitor. These results indicate that baflilomycin A1 treatment considerably blocked the HGF-induced MET and p-MET endocytosis, leading to the increased amounts of colocalized 
staining of both with LAMP1-positive late endosomes/lysosomes in the cells. Furthermore, this observation suggests that some components of Ephedrae herba extract might have stimulatory activity on the HGF-induced MET and p-MET endocytosis and subsequent degradation likely was mediated via the early/late endocytic pathways.

Activation of MET and its downstream signaling are inhibited by Ephedrae herba following HGF stimulation of human NSCLC cells. Our confocal immunofluorescence microscopy study described above demonstrated that Ephedrae herba extract considerably stimulated the endocytosis of MET and $\mathrm{p}$-MET and subsequent degradation via the early/late endocytic pathways in H1993 cells following HGF stimulation. Therefore, we hypothesized that Ephedrae herba might suppress MET activation and subsequently inhibit the successive PI3K-AKT signaling pathway.

To investigate this hypothesis, we analyzed the effect of Ephedrae herba extract pretreatment on the phosphorylation of AKT or p44/42 MAPK. Cells pretreated with or without Ephedrae herba extract were stimulated with $\mathrm{HGF}$ at $37^{\circ} \mathrm{C}$ for the indicated times. The lysates were analyzed with anti-p-MET, anti-p-AKT ${ }^{\text {S473 }}$, or anti-p-p44/42 MAPK antibodies by western blot analysis.

As shown in Fig. 5A and B, we observed an increase in MET phosphorylation even without HGF stimulation (0 h), and the increased levels of p-MET protein persisted in the cells over the 4-h incubation. The human NSCLC cell line H1993, which harbors MET gene amplification, was reported to overexpress MET receptors that were constitutively phosphorylated (10). Therefore, the increased MET phosphorylation we observed even without HGF stimulation is consistent with the previous findings (10). On the contrary, Ephedrae herba extract pretreatment markedly suppressed the HGF-induced MET phosphorylation and p-MET was decreased by 35,43 , and $71 \%$ at 0,1 , and $4 \mathrm{~h}$, respectively after HGF stimulation (Fig. 5A and B).

In addition, a rapid increase in $\mathrm{p}-\mathrm{AKT}^{\mathrm{S} 473}$ was observed in the untreated cells, and the level increased up to 24-fold that of the basal level after $2 \mathrm{~h}$ of HGF stimulation. In addition, this effect was sustained during the following 4-h incubation period (Fig. 5A and B). However, Ephedrae herba extract pretreatment significantly suppressed $\mathrm{AKT}^{\mathrm{S} 473}$ phosphorylation, and p-AKT ${ }^{5473}$ was decreased by 95,80 , and $94 \%$ at 1,2 , and $4 \mathrm{~h}$, respectively after HGF stimulation (Fig. 5A and B). Furthermore, an increase in p-p44/42 MAPK was observed in the untreated cells, with the level attaining a 4.3 -fold increase compared to the basal level after at $0.5 \mathrm{~h}$ of HGF stimulation; however, this effect gradually decreased during the 4-h incubation period (Fig. 5A and B). The inhibitory effect of Ephedrae herba extract on the expression of p-p44/42 MAPK was also evident in the cells, and p-p44/42 MAPK was decreased by 93 , 88 , and $93 \%$ at $0.5,1$, and $4 \mathrm{~h}$, respectively after HGF stimulation (Fig. 5A and B). These results indicate that Ephedrae herba extract had a strong inhibitory effect on MET phosphorylation and subsequent activation of the PI3K-AKT activation pathway in H1993 cells.

Next, we further analyzed the effect of Ephedrae herba extract on the HGF-induced degradation of MET in H1993 cells using western blot. As shown in Fig. 5, we found a gradual
HGF-dependent degradation of MET in the Ephedrae herba extract pretreated cells, and MET expression decreased by 8 , 23 , and $33 \%$ at 1,2 , and $4 \mathrm{~h}$ after HGF stimulation (Fig. 5A and B). In contrast, HGF-dependent MET degradation was not seen in the untreated cells. Furthermore, it should be noted that the protein expression levels of AKT and p44/42 MAPK were not changed by Ephedrae herba extract pretreatment during the 4-h incubation with HGF, indicating that Ephedrae herba might selectively stimulate the HGF-dependent downregulation of MET/p-MET via the early/late endocytic pathways.

\section{Discussion}

In the present study, we evaluated the novel role of Ephedrae herba and demonstrated that it exerted a considerable suppressive effect on the phosphorylation of MET, leading to the loss of MET and p-MET in human H1993 NSCLC cells. Using confocal immunofluorescence microscopy, we found a significant reduction of endogenous MET and $\mathrm{p}$-MET protein expression in H1993 cells pretreated with Ephedrae herba extract for $4 \mathrm{~h}$. Furthermore, MET and p-MET was exclusively localized in the plasma membrane at a cell-cell contact sites in H1993 cells and no colocalization was observed with the early endosomes or late endosomes/lysosomes. The pretreatment of cells with Ephedrae herba extract markedly decreased the levels of plasma membrane-associated MET and p-MET, and the resultant intracellular MET/p-MET staining was distributed throughout the cytoplasm, and large amounts were clearly colocalized with the early/late endosome marker proteins (SNX1 and LAMP1). These results demonstrate that pretreatment of cells with Ephedrae herba extract inhibited MET phosphorylation and induced the loss of MET. Moreover, the results also suggest that plasma membrane-associated MET and p-MET might be rapidly endocytosed in the extracttreated cells following HGF-stimulation, and then subsequently sorted to endosomes/lysosomes. This assumption was further confirmed by the observation that bafilomycin A1 treatment considerably blocked HGF-induced MET and p-Met endocytosis followed by their degradation in the Ephedrae herba extract-pretreated cells.

We further used western blot analysis to demonstrate that Ephedrae herba extract pretreatment markedly suppressed MET phosphorylation following HGF stimulation during the 4-h incubation (Fig. 5). We also showed evidence that MET protein gradually disappeared from the cells during the 4-h stimulation with HGF. In contrast, HGF-dependent MET degradation was not observed in the non-pretreated cells. Previous studies showed $M E T$ gene amplification and overexpression of MET receptors, which were constitutively phosphorylated and activated in a human H1993 NSCLC cell line (10). Therefore, our results showing the suppression of MET phosphorylation by Ephedrae herba during HGF stimulation might be attributable to the enhanced endocytic translocation of MET/p-MET from the plasma membranes via early endosomes to late endosomes/lysosomes. Alternatively, we also postulated that Ephedrae herba might be able to suppress MET phosphorylation followed by its downregulation without HGF stimulation in H1993 cells. Here, we also showed that Ephedrae herba significantly suppressed the phosphorylation of $\mathrm{AKT}^{\mathrm{S} 473}$ and p44/42 MAPK during the 4-h incubation with HGF (Fig. 5). 
A p-MET

MET
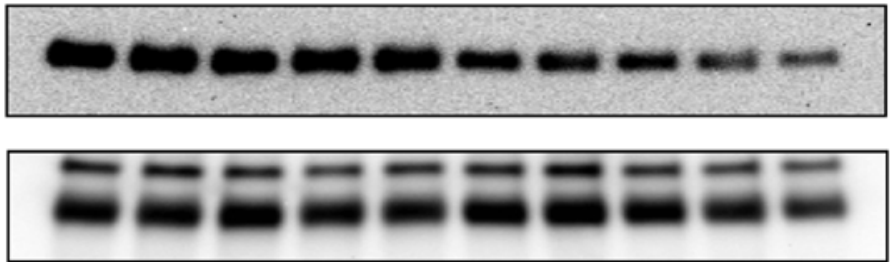

p-AKT

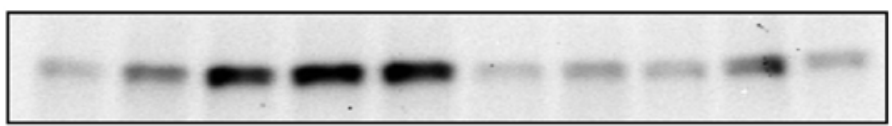

AKT

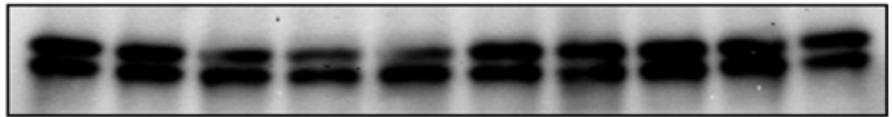

p-MAPK

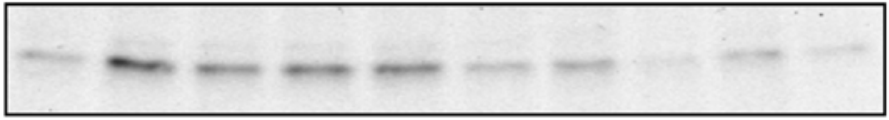

MAPK

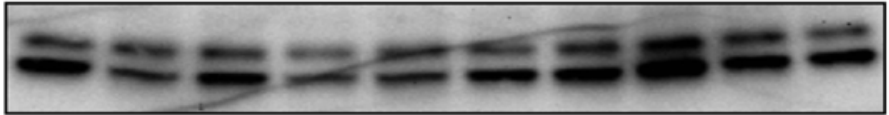

$\beta$-actin

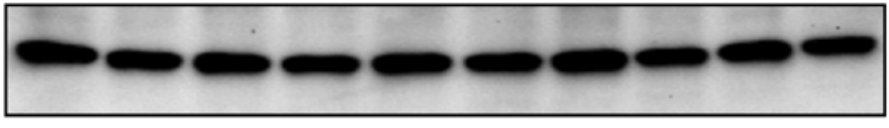

$+\mathrm{HGF}(\mathrm{h})$
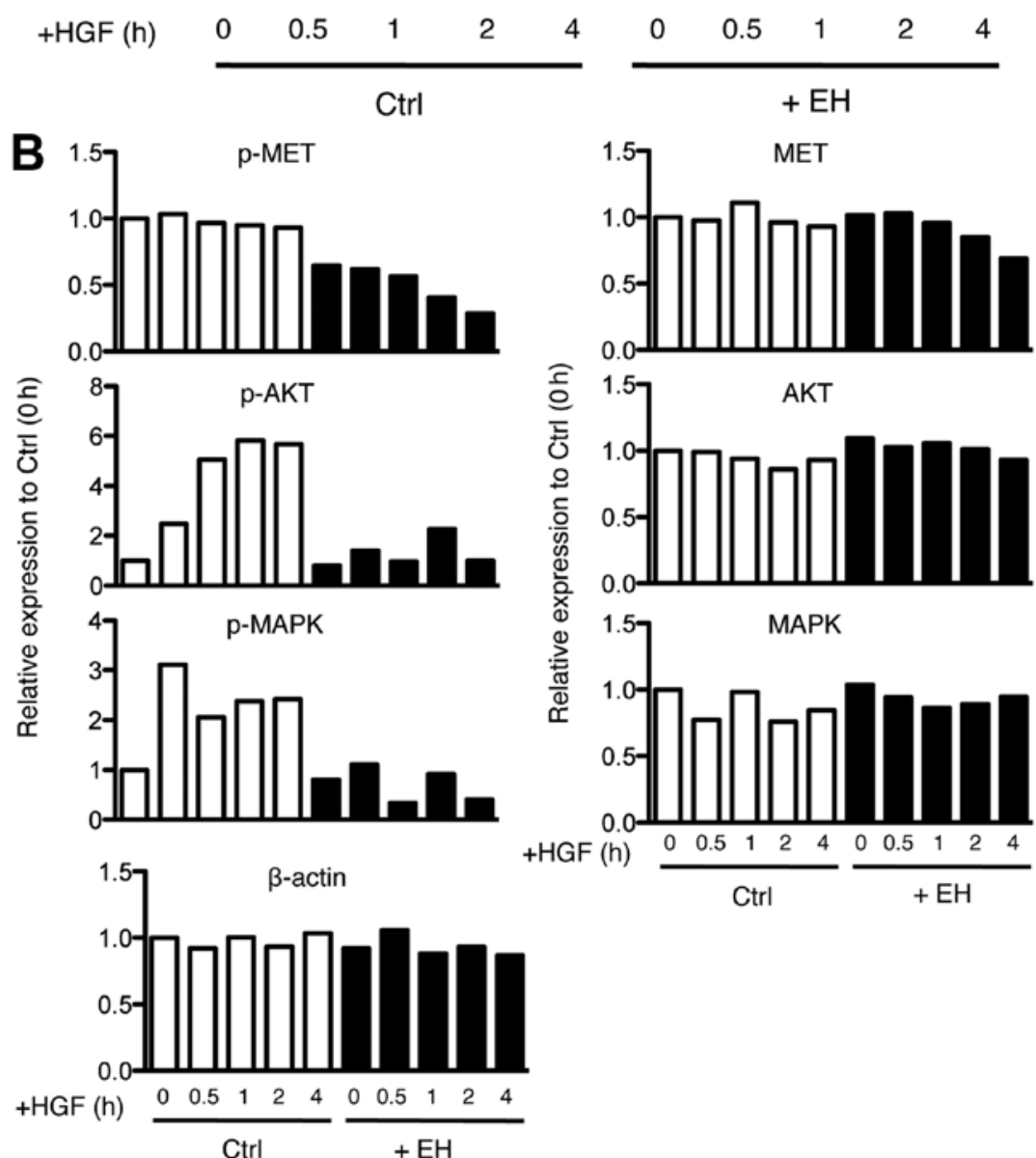

(h)

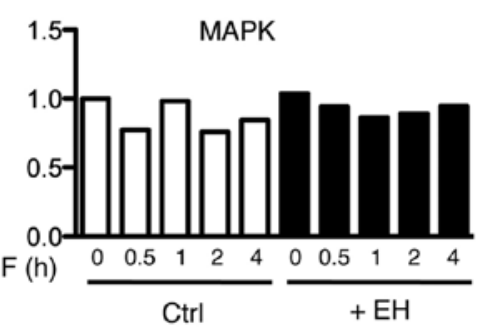

$+\mathrm{EH}$

Figure 5. Effect of Ephedrae herba on the activation of MET tyrosine kinase receptor and downstream signaling in human H1993 NSCLC cell line. (A) Expression of p-MET, p-AKT (Ser473), p-MAPK (p-p44/42 MAPK), total MET, total AKT, and total p44/42 MAPK (MAPK) before and after 0.5, 1, 2, or $4 \mathrm{~h}$ of HGF stimulation in H1993 cells pretreated with or without Ephedrae herba extract was determined by western blotting. $\beta$-actin was used as a loading control. (B) The quantitative analysis of the western blots is shown. Relative expression levels of p-MET, p-AKT (Ser473), p-MAPK (p-p44/42 MAPK), total MET, total AKT, and total p44/42 MAPK (MAPK) are shown and the values are normalized to each phosphorylated or unphosphorylated protein before HGF stimulation in $\mathrm{H} 1993$ cells. In the case of p-MAPK, the relative expression levels of phosphorylated form of p44/42 MAPK (upper band) was determined. The results shown are representative of three independent experiments. p-MET, phosphorylated human MET tyrosine kinase receptor; p-AKT, phosphorylated AKT (protein kinase B); p-MAPK, phosphorylated p44/42 MAPK. 
These results indicate that Ephedrae herba might have a selective inhibitory effect on MET phosphorylation and subsequent activation of the PI3K-AKT and RAS/MAPK activation pathways in H1993 cells. Furthermore, our data also support previous findings that Ephedrae herba inhibits HGF-induced cancer cell motility via suppression of HGF/Met-Akt signaling through the reduction of MET tyrosine kinase activity in human MDA-MB-231 breast cancer cells $(23,24)$.

We recently reported the novel observation that large amounts of SNX1, a family of sorting nexin proteins that are believed to play a role in the endocytic trafficking of EGFR (33,34), are localized in the aggregated vesicular structures of early endosomes where the internalized p-EGFR is also accumulated (30,31). Furthermore, we reported that the depletion of endogenous SNX1 by siRNA stimulates endocytosis and the ligand-induced downregulation of MET/p-MET and EGFR/p-EGFR while it increases p-MET and p-EGFR protein expression in gefitinib-resistant cells $(19,32)$. Accordingly, we postulate that SNX1 might negatively regulate ligand-dependent downregulation of MET and EGFR as well as their phosphorylation via the early/late endocytic pathways in human lung cancer cells. Therefore, our present data demonstrating the suppressive role of Ephedrae herba on the phosphorylation of MET and its subsequent enhanced downregulation appear consistent with those demonstrating the role of SNX1 in HGF-induced phosphorylation and endocytosis of MET via the endocytic pathway in human lung cancer cells $(19,32)$. Although the detailed mechanisms underlying the effect of Ephedrae herba on endocytic trafficking of transmembrane tyrosine kinase receptors such as MET remain unclear, we inferred that some of its components might perturb the tightly regulated processes involved in the ligand-induced MET endocytosis via the early/late endocytic pathways in the cells.

Engelman et al (9) previously reported that MET amplification leads to acquired resistance to gefitinib and erlotinib in patients with lung cancer by activating erb-b2 receptor tyrosine kinase 3 (ERBB3) signaling. In addition, another study reported that MET amplification occurs with or without a representative secondary T790M mutation in EGFR mutant lung tumors with acquired resistance to gefitinib or erlotinib (37). Accordingly, we inferred that pretreatment of the cells with Ephedrae herba extract enhanced the downregulation of HGF-stimulated MET, which might have affected the sensitivity of the human NSCLC cells to the EGFR-tyrosine kinase inhibitor (TKI), gefitinib. In the present study, the identification and characterization of the main biologically active constituents of the Ephedrae herba extract proved to be difficult due to its complex composition. Further studies to identify and investigate the compounds in Ephedrae herba that are biologically active against HGF/MET activation and signaling in NSCLC cell lines are now in progress.

\section{References}

1. Di Renzo MF, Narsimhan RP, Olivero M, Bretti S, Giordano S, Medico E, Gaglia P, Zara P and Comoglio PM: Expression of the Met/HGF receptor in normal and neoplastic human tissues. Oncogene 6: 1997-2003, 1991.

2. Comoglio PM and Boccaccio C: The HGF receptor family: Unconventional signal transducers for invasive cell growth. Genes Cells 1: 347-354, 1996.
3. Jeffers M, Rong S and Vande Woude GF: Hepatocyte growth factor/scatter factor-Met signaling in tumorigenicity and invasion/metastasis. J Mol Med (Berl) 74: 505-513, 1996.

4. Pennacchietti S, Michieli P, Galluzzo M, Mazzone M, Giordano S and Comoglio PM: Hypoxia promotes invasive growth by transcriptional activation of the met protooncogene. Cancer Cell 3: 347-361, 2003.

5. Kuniyasu H, Yasui W, Kitadai Y, Yokozaki H, Ito $\mathrm{H}$ and Tahara E: Frequent amplification of the c-met gene in scirrhous type stomach cancer. Biochem Biophys Res Commun 189: 227-232, 1992.

6. Kijima Y, Hokita S, Yoshinaka H, Itoh T, Koriyama C, Eizuru Y, Akiba $S$ and Aikou T: Amplification and overexpression of c-met gene in Epstein-Barr virus-associated gastric carcinomas. Oncology 62: 60-65, 2002.

7. Nakazawa K, Dobashi Y, Suzuki S, Fujii H, Takeda Y and Ooi A: Amplification and overexpression of c-erbB-2, epidermal growth factor receptor, and c-met in biliary tract cancers. J Pathol 206: 356-365, 2005.

8. Miller CT, Lin L, Casper AM, Lim J, Thomas DG, Orringer MB, Chang AC, Chambers AF, Giordano TJ, Glover TW, et al: Genomic amplification of MET with boundaries within fragile site FRA7G and upregulation of MET pathways in esophageal adenocarcinoma. Oncogene 25: 409-418, 2006

9. Engelman JA, Zejnullahu K, Mitsudomi T, Song Y, Hyland C, Park JO, Lindeman N, Gale CM, Zhao X, Christensen J, et al: MET amplification leads to gefitinib resistance in lung cancer by activating ERBB3 signaling. Science 316: 1039-1043, 2007.

10. Lutterbach B, Zeng Q, Davis LJ, Hatch H, Hang G, Kohl NE, Gibbs JB and Pan BS: Lung cancer cell lines harboring MET gene amplification are dependent on Met for growth and survival. Cancer Res 67: 2081-2088, 2007.

11. Nakamura T, Teramoto $\mathrm{H}$ and Ichihara A: Purification and characterization of a growth factor from rat platelets for mature parenchymal hepatocytes in primary cultures. Proc Natl Acad Sci USA 83: 6489-6493, 1986.

12. Birchmeier C and Gherardi E: Developmental roles of HGF/SF and its receptor, the c-Met tyrosine kinase. Trends Cell Biol 8: 404-410, 1998.

13. Birchmeier C, Birchmeier W, Gherardi E and Vande Woude GF: Met, metastasis, motility and more. Nat Rev Mol Cell Biol 4: 915-925, 2003.

14. Ullrich A and Schlessinger J: Signal transduction by receptors with tyrosine kinase activity. Cell 61: 203-212, 1990.

15. Rodrigues GA and Park M: Autophosphorylation modulates the kinase activity and oncogenic potential of the Met receptor tyrosine kinase. Oncogene 9: 2019-2027, 1994.

16. Ma PC, Tretiakova MS, Nallasura V, Jagadeeswaran R, Husain AN and Salgia R: Downstream signalling and specific inhibition of c-MET/HGF pathway in small cell lung cancer: Implications for tumour invasion. Br J Cancer 97: 368-377, 2007.

17. Henne WM, Buchkovich NJ and Emr SD: The ESCRT pathway. Dev Cell 21: 77-91, 2011.

18. Yarden Y: The EGFR family and its ligands in human cancer signaling mechanisms and therapeutic opportunities. Eur J Cancer 37: 3-8, 2001.

19. Nishimura Y, Takiguchi S, Ito $S$ and Itoh K: Evidence that depletion of the sorting nexin 1 by siRNA promotes HGF-induced MET endocytosis and MET phosphorylation in a gefitinibresistant human lung cancer cell line. Int J Oncol 44: 412-426, 2014.

20. Nishimura Y, Takiguchi S, Ito S and Itoh K: EGF-stimulated AKT activation is mediated by EGFR recycling via an early endocytic pathway in a gefitinib-resistant human lung cancer cell line. Int J Oncol 46: 1721-1729, 2015.

21. Hyuga $S$, Hyuga $M$, Yamagata $S$, Yamagata $T$ and Hanawa $T$ : Mao-to, a Kampo medicine, inhibits migration of highly metastatic osteosarcoma cells. J Trad Med 21: 174-181, 2004.

22. Hyuga S, Hyuga M, Nakanishi H, Ito H, Watanabe K, Oikawa T and Hanawa T: Maoto, Kampo medicine, suppresses the metastatic potential of highly metastatic osteosarcoma cells. J Trad Med 24: 51-58, 2007.

23. Hyuga S, Shiraishi M, Hyuga M, Goda Y and Hanawa T: Ephedrae herba, a major component of maoto, inhibits the HGF-induced motility of human breast cancer MDA-MB-231 cells through suppression of c-Met tyrosine phosphorylation and c-Met expression. J Trad Med 28: 128-138, 2011.

24. Hyuga $S$ and Hanawa T: Basic research on the use of Kampo medicines to protect against cancer recurrence and metastasis. J Trad Med 30: 19-26, 2013. 
25. Amakura Y, Yoshimura M, Yamakami S, Yoshida T, Wakana D, Hyuga M, Hyuga S, Hanawa T and Goda Y: Characterization of phenolic constituents from ephedra herb extract. Molecules 18 : $5326-5334,2013$.

26. Hyuga S, Hyuga M, Yoshimura M, Amakura Y, Goda $Y$ and Hanawa T: Herbacetin, a constituent of ephedrae herba, suppresses the HGF-induced motility of human breast cancer MDA-MB-231 cells by inhibiting c-Met and Akt phosphorylation. Planta Medica 79: 1525-1530, 2013.

27. Nishimura $Y$, Higaki $M$ and Kato K: Identification of a precursor form of cathepsin D in microsomal lumen: Characterization of enzymatic activation and proteolytic processing in vitro Biochem Biophys Res Commun 148: 335-343, 1987.

28. Nishimura Y, Kawabata T and Kato K: Identification of latent procathepsins B and L in microsomal lumen: Characterization of enzymatic activation and proteolytic processing in vitro. Arch Biochem Biophys 261: 64-71, 1988.

29. Nishimura Y, Bereczky B and Ono M: The EGFR inhibitor gefitinib suppresses ligand-stimulated endocytosis of EGFR via the early/late endocytic pathway in non-small cell lung cancer cell lines. Histochem Cell Biol 127: 541-553, 2007.

30. Nishimura Y, Yoshioka K, Bereczky B and Itoh K: Evidence for efficient phosphorylation of EGFR and rapid endocytosis of phosphorylated EGFR via the early/late endocytic pathway in a gefitinib-sensitive non-small cell lung cancer cell line. Mol Cancer 7: 42, 2008.

31. Nishimura Y, Yoshioka K, Takiguchi S, Bereczky B, Nakabeppu Y and Itoh K: A role for SNX1 in the regulation of EGF-dependent phosphorylated EGFR endocytosis via the early/late endocytic pathway in a gefitinib-sensitive human lung cancer cells. Curr Signal Transduct Ther 6: 383-395, 2011.
32. Nishimura Y, Takiguchi S, Yoshioka K, Nakabeppu Y and Itoh K: Silencing of SNX1 by siRNA stimulates the ligand-induced endocytosis of EGFR and increases EGFR phosphorylation in gefitinib-resistant human lung cancer cell lines. Int J Oncol 41: 1520-1530, 2012.

33. Worby CA and Dixon JE: Sorting out the cellular function of sorting nexins. Nat Rev Mol Cell Biol 3: 919-931, 2002.

34. Kurten RC, Cadena DL and Gill GN: Enhanced degradation of EGF receptors by a sorting nexin, SNX1. Science 272: 1008-1010, 1996.

35. Kornfeld S and Mellman I: The biogenesis of lysosomes. Annu Rev Cell Biol 5: 483-525, 1989.

36. Sandoval IV, Arredondo JJ, Alcalde J, Gonzalez-Noriega A, Vandekerckhove J, Jimenez MA and Rico M: The residues Leu (Ile) 475-Ile (Leu) 476, contained in the extended carboxyl cytoplasmic tail, are critical for targeting of the resident lysosomal membrane protein LIMPII to lysosomes. J Biol Chem 269: 6622-6631, 1994.

37. Bean J, Brennan C, Shih JY, Riely G, Viale A, Wang L, Chitale D, Motoi N, Szoke J, Broderick S, et al: MET amplification occurs with or without T790M mutations in EGFR mutant lung tumors with acquired resistance to gefitinib or erlotinib. Proc Natl Acad Sci USA 104: 20932-20937, 2007. 